\title{
Ciência, tecnologia e inovação para o desenvolvimento do Brasil
}

Science, technology and innovation for the development of Brazil

\author{
M. N. Borges ${ }^{1, *}$ \\ ${ }^{1}$ Departamento de Engenharia Elétrica, Universidade Federal de SJDR, 36.307-362, SJDR-MG, Brasil \\ ${ }^{1}$ Conselho Nacional das Fundações Estaduais de Amparo à Pesquisa, CONFAP, 70.322-915, Brasília-DF, Brasil
}

*marionetoborges@uol.com.br

(Artigo convidado para a edição comemorativa dos 10 anos da Scientia Plena)

\begin{abstract}
Este artigo apresenta o contexto científico nacional e internacional com foco na trajetória das atividades de ciência, tecnologia e inovação no Brasil ao longo dos últimos anos e na perspectiva que pode ser inferida a partir do histórico traçado. Demonstra-se que o País não pode mais depender apenas do sucesso alcançado no indicador de produção científica indexada. Precisa, urgentemente e de forma ágil, mudar de patamar no desenvolvimento tecnológico e na inovação. O artigo mostra que é possível melhorar a competitividade nacional com base numa política séria e consistente de valorização do trinômio ciência, tecnologia e inovação como pilares para garantir o desenvolvimento social e econômico sustentável do País. Essa política requer, entre outros elementos, um investimento perene e robusto e um arcabouço legal adequado que permita o avanço da pesquisa e da inovação. $\mathrm{O}$ artigo apresenta recomendações que poderão por um lado, indicar os gargalos a serem resolvidos e por outro, ajudar a elaboração de uma política consistente para o desenvolvimento nacional.

Palavras-chave: ciência, inovação, desenvolvimento
\end{abstract}

This paper aims at presenting the national and international scientific context focusing not only on the historic background of Brazil and but also on the future perception of a new context to be built based on science, technology and innovation. It is demonstrated that Brazil can no longer depend only on the success of the recent years regarding the scientific production. It must also change, urgently and quickly, the level of technology and innovation. The paper tries to demonstrate that it is possible to improve the national competitiveness based on a consistent policy designed to emphasize science, technology and innovation. This policy requires, among other issues, a strong and permanent investment and an appropriate set of laws, which will allow the advance of research and innovation in the country. The paper also presents some recommendations for, on the one hand, overcome the hurdles and, on the other, help on the design of a consistent policy for the development of the country.

Keywords: science, innovation, development

\section{INTRODUÇÃO}

Nos dias atuais é consenso geral que a ciência e a tecnologia crescem de maneira exponencial e tem como consequência um forte impacto na vida das pessoas por estar resultando em inovações que são disponibilizadas em taxas assustadoras. Não foi sempre assim. A ciência começou a ser forjada pela civilização ocidental há dois mil e quinhentos anos atrás. Aristóteles, por sua proeminência e pelo seu dom de fazer descobertas, aprofundava o conhecimento do mundo existente e criava uma forma de ciência. A ciência de Aristóteles subsistiu durante dois mil anos e foi ensinada e debatida nos grandes centros de conhecimento como Oxford, Paris e Frankfurt [1].

Muita coisa mudou e, especialmente na segunda metade do século passado - após a $2^{\mathrm{a}}$ guerra mundial, a ciência passou a ser vista associada com a tecnologia. O domínio da ciência e da tecnologia era a garantia de soberania para os povos e nações que dominavam o conhecimento. Ao final do século e, em particular, no início deste, o binômio já era insuficiente para satisfazer as demandas da sociedade e para garantir o pleno desenvolvimento dos países num cenário altamente 
competitivo. Surge então o tripé: Ciência, Tecnologia e Inovação - CT\&I. Por trás, como força propulsora, a necessidade de expandir as fronteiras do conhecimento, agregar novidades e assegurar seu impacto na melhoria da qualidade de vida da sociedade moderna.

Do ponto de vista da produção do conhecimento científico, podemos considerar as últimas décadas como um momento positivo para o Brasil. Isso é atestado pelos indicadores científicos de produção de artigos, em periódicos indexados, que cresceu de forma exponencial nos últimos vinte anos. Isso graças aos investimentos perenes na pós-graduação nos últimos cinquenta anos feitos pela CAPES e pelo CNPq. Esse índice já atinge a marca de 2,7\% da produção mundial conforme publicado na revista Science [2].

No entanto, falta ainda avançar no sentido de transformar esses índices de produção científica, em indicadores de desenvolvimento tecnológico e inovação. O Brasil só será desenvolvido, econômica e socialmente, quando tiver uma sólida e robusta plataforma não só científica, mas também tecnológica e de inovação. Exemplos não faltam na Europa, América do Norte e Ásia demonstrando que ao investir em ciência e tecnologia, os países mudaram o patamar de qualidade de vida de suas sociedades. As grandes potências mundiais incentivam a inovação em suas pesquisas e em suas tecnologias visando a competitividade de suas economias. Este artigo defende que o Brasil - pode e deve - seguir o mesmo caminho. Portanto, as agências de fomento devem induzir não só os pesquisadores e cientistas, mas também as instituições (universidades, centros de pesquisa e indústria), a se debruçarem sobre a inovação como elemento essencial para diminuir esse, ainda preocupante, fosso que separa o Brasil dos países plenamente desenvolvidos.

\section{HISTÓRICO NACIONAL E INTERNACIONAL}

Estudos sobre o contexto internacional têm demonstrado que o desenvolvimento das nações ocorre, em parte, motivado pelas demandas emanadas das pessoas que buscam uma qualidade de vida cada vez melhor. Para cada país as demandas são proporcionais ao tamanho de sua população e para isso requerem condições específicas para serem atendidas.

Pode-se então sintetizar em três elementos as bases que dão aos países as condições necessárias para se desenvolverem no contexto global e se tornarem potências globais. O tamanho da população, os recursos/insumos disponíveis e a dimensão e diversidade da economia formam elementos que permitem inferir a perspectiva de cada país em se tornar (ou não) uma potência. A figura 1 mostra estas condições em um diagrama com interseções. Verifica-se que atendem à todas as condições mencionadas os países das três interseções que formam o bloco dos BRICS (centro da figura 1). Os EUA, a maior e mais diversificada economia do planeta, que certamente também preenche essas condições, não foi considerado nesta análise.

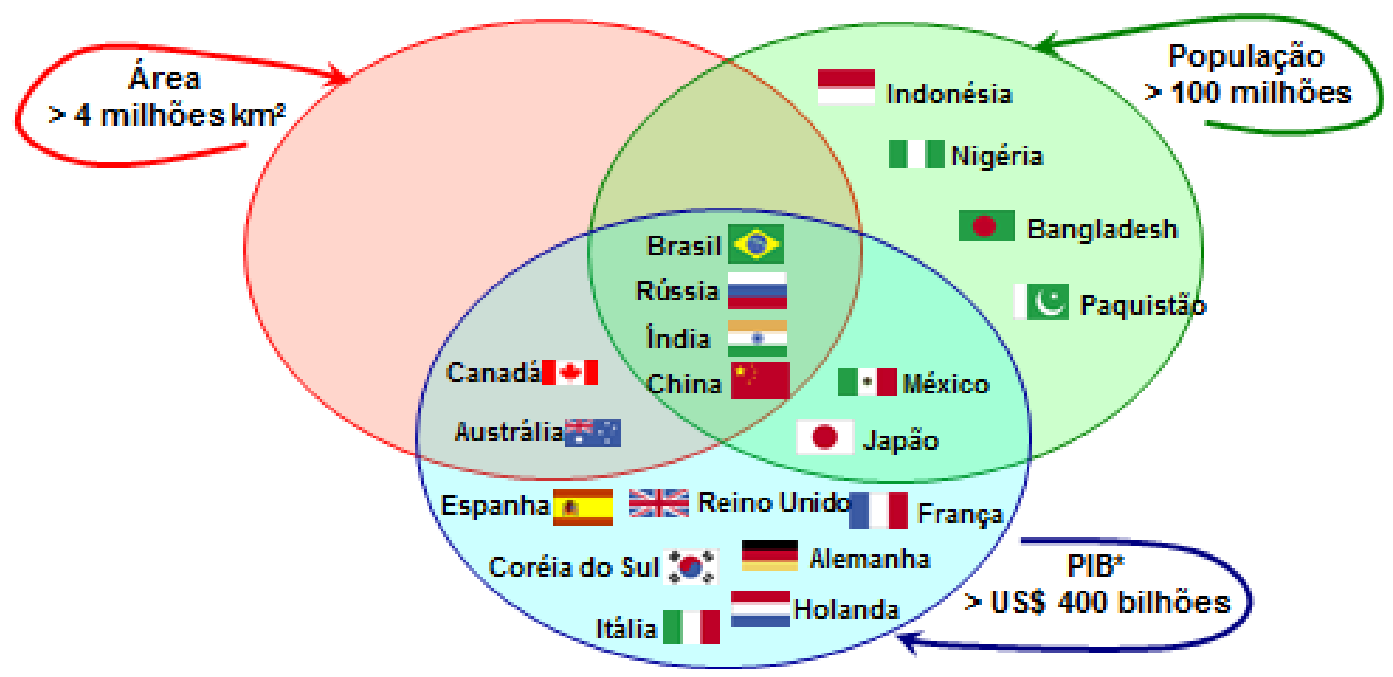

Figura 1 - Modelo desenvolvido por Ronald Dauscha - modificado pelo autor 
Reunidas estas condições mencionadas e apresentadas na figura 1, as políticas públicas são os motores que podem levar as nações ao desenvolvimento pleno e sustentável. Entre essas políticas a educação e o tripé ciência, tecnologia e inovação têm papel absolutamente crucial.

A história da ciência no Brasil e, em particular, do fomento à ciência é muito recente e tem pouco mais de meio século. Comparado ao contexto mundial, especialmente o europeu cuja história é milenar, apresenta uma realidade que precisa ser bem equacionada se se deseja colocar o País entre as potências produtoras de conhecimento. Na década de cinquenta, o Brasil cria suas principais agências de fomento federais: a Coordenação de Aperfeiçoamento de Pessoal de Nível Superior - CAPES e o Conselho Nacional de Desenvolvimento Científico e Tecnológico - CNPq. Essas importantes iniciativas foram responsáveis pelo crescimento da pós-graduação e da produção científica e - consequentemente - por grande parte sucesso que hoje o País apresenta no cenário internacional, no que diz respeito às publicações científicas.

A base do desenvolvimento científico e tecnológico está na formação de pesquisadores e cientistas. No Brasil, as bolsas de pós-graduação, para incentivar a formação de mestres e doutores, fazem parte do universo acadêmico, sendo fundamental para o incremento da produção científicotecnológica e o sucesso da ciência nacional. Além dos benefícios práticos, a bolsa cumpre o papel de formar pesquisadores e tem a função de despertar a vocação para a ciência. Os dados da formação de mestres e doutores mostram que tem havido um crescimento exponencial no número de concluintes de mestrado e doutorado [3]. Recrutados principalmente pelas universidades e centros de pesquisa estes cientistas foram responsáveis pelo aumento expressivo da produção indexada nacional.

O Brasil é hoje o $13^{\circ}$ país produtor de ciência do mundo sendo responsável por 2,7\% de toda produção mundial indexada, como já mencionado. Isso representa um avanço significativo se se considerar que neste intervalo houve um crescimento exponencial no número de publicações acompanhando o crescimento do número de pesquisadores formados. Acelerar ainda mais a produção nacional e direcioná-la para áreas estratégicas de importância para o desenvolvimento do País é uma das recomendações deste artigo.

Este avanço se deve também ao maior volume de recursos disponibilizados para que estes pesquisadores, formados em números crescentes, tenham podido executar seus projetos de pesquisa. Recursos estes provenientes no nível federal, principalmente, dos Fundos Setoriais criados nos anos 2000, que deu origem ao Fundo Nacional de Desenvolvimento Científico e Tecnológico - FNDCT. Deve-se considerar também os investimentos feitos pelos estados a partir da criação de suas Fundações de Amparo à Pesquisa - FAPs, que têm contribuído fortemente para o crescimento da produção científica nacional. Recursos estes, federais e estaduais, que recentemente têm sido perigosamente ameaçados devido à crise atual na economia do País quando - equivocadamente - os governos cortam primeiros os orçamentos de CT\&I.

Se por um lado, os indicadores de produção científica dão destaque ao País, por outro lado, os resultados advindos da transformação dessa ciência em desenvolvimento tecnológico e inovação ainda são constrangedores. Os indicadores de propriedade intelectual, sejam eles marcas, patentes, cultivares, programas de computador ou desenhos industriais, estão muito aquém do necessário para garantir ao País uma condição de geração de riqueza interna e competitividade no cenário internacional. No caso de patentes depositadas nos Estados Unidos, para ficar apenas num exemplo, o Brasil detém apenas $0,2 \%$ do total. A figura 2 apresenta os indicadores socioeconômicos e de CT\&I do Brasil em relação ao mundo em valores percentuais [4]. 


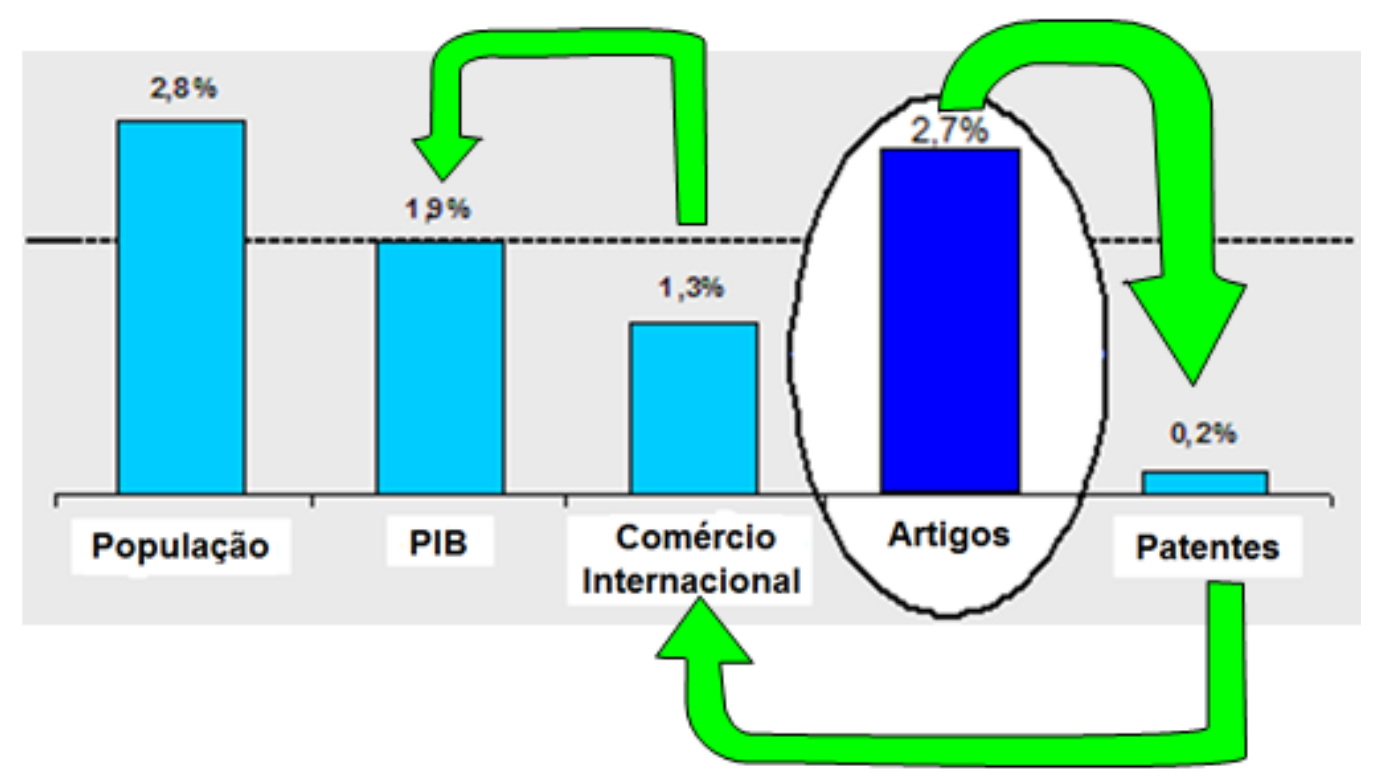

Figura 2 - Indicadores do Brasil em relação ao mundo (fonte MCT modificado)

Demonstra-se, portanto, a necessidade de transformar o conhecimento científico, produzido majoritariamente nas universidades e centros de pesquisa, em tecnologia e inovação que, ao serem incorporados nos produtos nacionais, tornam estes mais competitivos melhorando a balança comercial e gerando riqueza que aumenta o Produto Interno Bruto - PIB e, por consequência, melhorando qualidade de vida no País (ciclo indicado pelas setas verdes).

Na busca de corrigir essa discrepância, entre ciência e inovação, o País criou no final da década de 70 a Financiadora de Estudos e Projetos - FINEP. Atualmente a FINEP, como secretariaexecutiva do FNDCT, se autodenomina "Agência de Inovação". Muitos programas e ações têm sido concebidos para fomentar a inovação desde então, mas este é um desafio hercúleo que o Brasil ainda tem que enfrentar. Certamente a irregularidade no fluxo de investimentos e a elevada burocracia associada aos programas de incentivo à inovação têm desestimulado os empresários a buscar apoio nos programas públicos da área.

O momento para começar o processo de investimento maciço em educação e CT\&I não pode mais tardar pois o País passa pelo que é conhecido como bônus populacional. A figura 3 mostra que até o final do século passado a maior parcela da população brasileira estava concentrada na faixa etária de 0 a 24 (retângulo vermelho). Isso significa que era uma população de jovens e crianças que não (ou pouco) poderiam contribuir para o trabalho e a geração de riqueza. Nos próximos anos haverá uma mudança indicando que, por volta de 2035, teremos a maior parte da população na faixa etária de 25 a 65 anos, período mais produtivo do cidadão economicamente ativo e, portanto, o momento de dar um salto no desenvolvimento nacional.

Portanto, é urgente preparar essas pessoas por meio de uma educação de qualidade, do ensino fundamental à pós-graduação, e fazer investimentos sólidos em CT\&I para que se possa transformar o Brasil em uma potência não só econômica, mas também tecnológica, científica, social e cultural. Caso isso não seja feito o País corre o sério risco de, após a metade deste século, se tornar um país velho e pobre. 


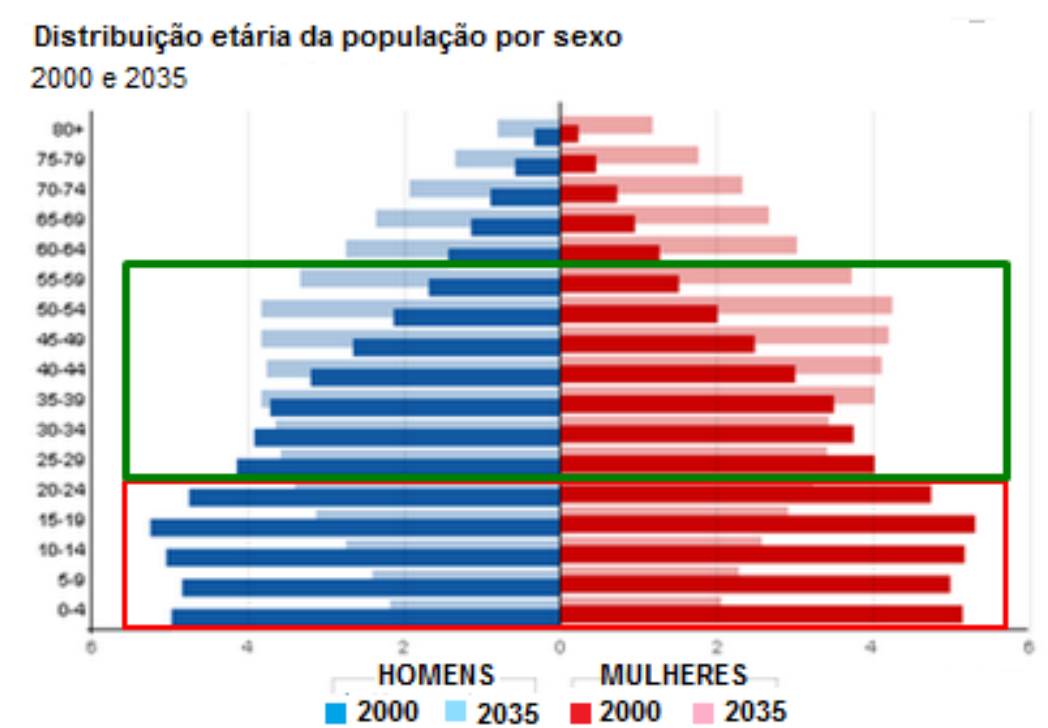

Figura 3 - Composição populacional do Brasil em 2000 e em 2035 (fonte IPEA)

\section{CENÁRIO INTERNACIONAL}

O cenário internacional aponta para uma realidade em que a competição entre os países se dá - cada vez mais - pelo domínio do conhecimento. O desenvolvimento sustentável, neste século do conhecimento, é baseado na geração de riqueza com lastro que, por sua vez, necessariamente depende da ciência, tecnologia e inovação. Com base nessa premissa e no fato de que quem produz ciência, tecnologia e inovação são os pesquisadores e cientistas, fica caracterizada a necessidade de o País ainda investir mais - e de forma estratégica - na formação de pesquisadores como já defendido anteriormente neste artigo.

Se por um lado esta formação de mestres e doutores é um dos bons resultados que o País tem apresentado recentemente, verifica-se no cenário internacional que o número de pesquisadores por habitantes é ainda muito baixo no Brasil. A figura 4 mostra na vertical o número de pesquisadores por mil habitantes e na horizontal o PIB per capita. Em destaque o Brasil, a Coreia, o Japão e os Estados Unidos. Verifica-se que o Brasil apresenta 0,5 pesquisador por 1000 habitantes enquanto a Coreia apresenta número próximo de quatro, o Japão mais de cinco e os Estados Unidos próximo de cinco. Isso significa que o País ainda tem muito o que avançar neste importante indicador.

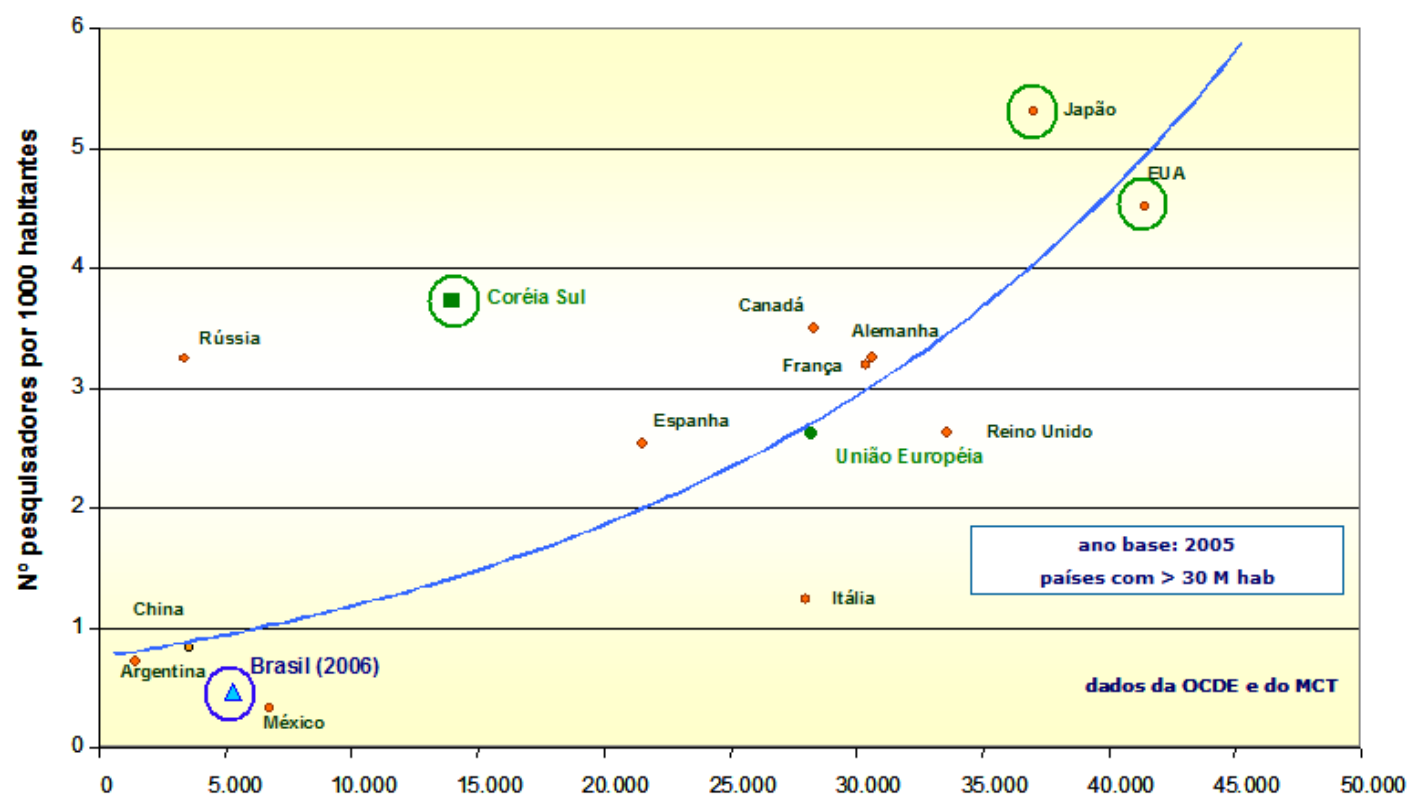

Figura 4 - Número relativo de pesquisadores em relação ao PIB dos países (fonte MCTI) 
Outra observação importante obtida na figura 4 é que, quanto maior o número de pesquisadores em relação à população maior é o PIB per capita de um país. A figura 4 também desmonta o mito, muitas vezes apresentado ao público leigo, de que o Brasil forma muitos mestres e doutores que não têm onde trabalhar. Primeiro, os dados da figura 4 mostram o contrário precisamos de mais pesquisadores. Segundo, ainda existe no País a ideia de que mestres e doutores são formados para atuar apenas nas universidades. Enquanto no Brasil aproximadamente $66 \%$ dos pesquisadores estão nas universidades e apenas $26 \%$ nas empresas, na Coreia, Japão e Estados Unidos este número não ultrapassa $7 \%$ nas universidades e está próximo de $70 \%$ nas empresas [5].

Certamente para manter e acelerar os avanços na produção científica e ao mesmo tempo corrigir a distorção descrita é necessário, entre outras coisas que ainda serão discutidas neste artigo, investimentos robustos e perenes - vale enfatizar. O Brasil investe hoje aproximadamente 1,14\% de seu PIB em CT\&I. A figura 4 apresenta o percentual do PIB investido em CT\&I ao longo dos anos comparado com outros países já citados. O ponto de destaque é 2008 quando houve a grande crise econômica mundial. A figura 5 mostra que a maioria dos países passa a investir mais em CT\&I como alternativa de superar a crise tornando suas economias mais competitivas. Verifica-se que o Brasil, indicado pela linha marrom, não teve crescimento nos investimentos no mesmo período. De fato, quando forem apurados os dados de $2012 \mathrm{em}$ diante, vai se verificar que houve um decréscimo nestes investimentos tão estratégicos para um país que pretende avançar no seu desenvolvimento.

Outra característica do percentual de investimento que deve ser considerada é sua composição quanto à participação do setor público e do setor privado. Neste caso a tabela 1 apresenta dados importantes como o fato de que os investimentos públicos no Brasil ainda que em patamares razoáveis precisam crescer. No entanto os investimentos privados têm que crescer muito mais para termos situação semelhante aos países desenvolvidos. Esse diagnóstico já é aceito pelos empresários que, em 2009, criaram o Movimento Empresarial pela Inovação [6].

A análise, das figuras 4 e 5, leva à conclusão que duas recomendações são importantes. A primeira é que as agências públicas que fomentam a pós-graduação têm que aumentar a oferta de cursos de pós-graduação - com foco em áreas estratégicas para o País e por consequência também aumentar o número de bolsas de mestrado e doutorado. Para cumprir a primeira recomendação os governos (federal e estaduais) devem investir mais em suas agências de fomento para ampliar a quantidade de bolsas concedidas. A segunda é que tanto o setor público como o privado precisam investir muito mais ainda em inovação. Para isso se faz necessário a elaboração de uma política de estado que seja consistente, que tenha recursos suficientes e que seja amparada por um arcabouço legal que dê segurança jurídica para os pesquisadores, para as agências de fomento e para o setor empresarial que decidir por investir nesse caminho.

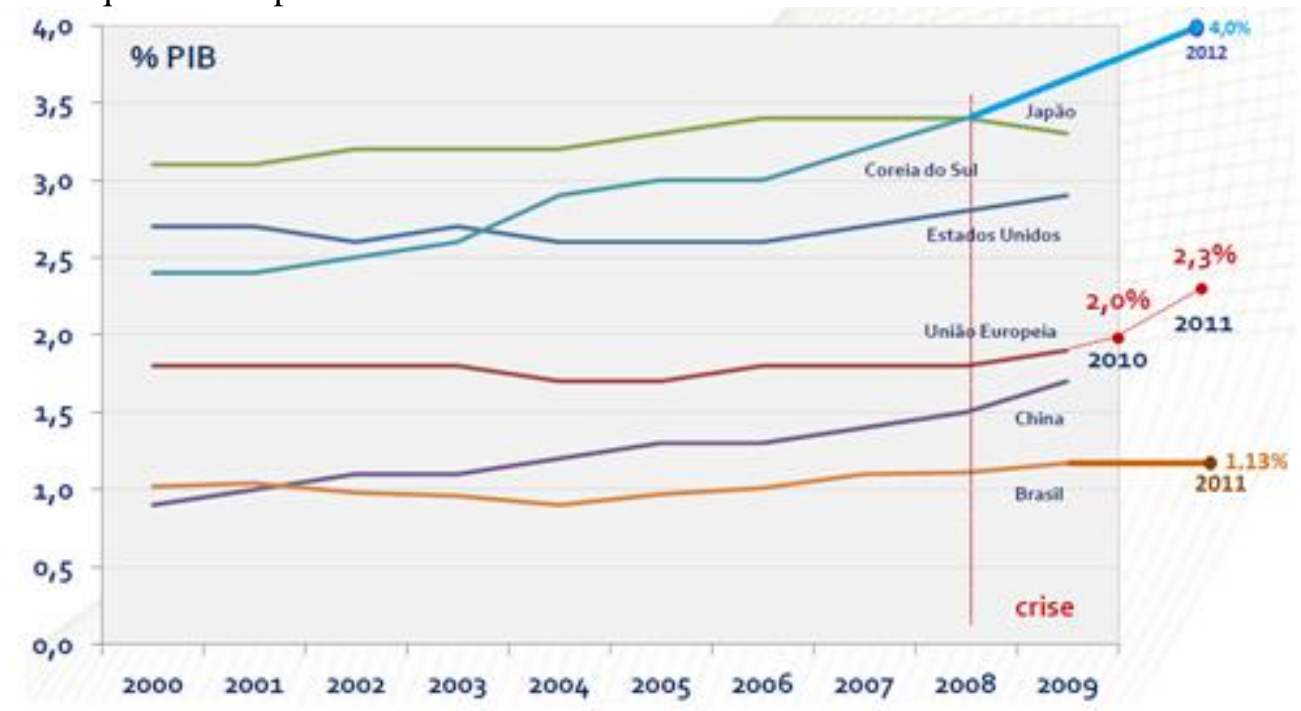

Figura 5 - Percentual de investimentos em CT\&I em relação ao PIB (fonte MCTI) 
Considerando os dados da tabela 1 , fica evidente que o setor empresarial - interessado direto que é na formação de pesquisadores para atuar na inovação das empresas - deve também participar, diretamente ou via os incentivos existentes, nos investimentos a serem feitos em CT\&I. Iniciativa neste sentido têm sido feitas como por exemplo a Lei de Inovação (2004) e Lei do Bem (2006). No entanto a burocracia e a falta de segurança jurídica têm impedido que o setor empresarial invista em inovação. Para isso, uma iniciativa concebida pelo CONFAP e CONSECTI, em 2011, foi apresentada ao Congresso Nacional para criar um arcabouço legal específico para CT\&I. Esta proposta ficou conhecida como Código Nacional de CT\&I e foi sancionada em janeiro de 2016 tornando-se a Lei $n^{\circ}$ 13.423/2016 - tema que será abordado neste artigo.

Tabela 1 - Investimentos privados e públicos em P\&D em percentual do PIB (fonte MCTI)

\begin{tabular}{c|c|c|c}
\hline País & Privado & Público & Total \\
\hline Japão & 2,4 & 0,8 & 3,2 \\
\hline Coreia & 3,0 & 1,0 & 4,0 \\
\hline EUA & 2,0 & 0,8 & 2,8 \\
\hline Brasil & 0,55 & 0,59 & 1,14 \\
\hline
\end{tabular}

\section{CIÊNCIA, TECNOLOGIA E INOVAÇÃO}

Para superar o desafio apresentado deve-se enfrentar a realidade, hoje distorcida, em relação ao trinômio: Ciência, Tecnologia e Inovação. A figura 6 (A) é uma representação gráfica da realidade vigente, fruto dos investimentos nacionais feitos nos últimos 65 anos. Como já descrito anteriormente estes investimentos resultaram num avanço significativo da ciência nacional, mas, por outro lado, não houve o correspondente avanço nem na tecnologia e nem na inovação. Isso produziu um desenvolvimento distorcido expresso pelo diagrama tridimensional da figura 6 (A).

A ação requerida agora e para o futuro é, além de continuar investindo e acelerando a produção científica nacional, atuar de maneira estrutural e estratégica para avançar no desenvolvimento tecnológico e na inovação no contexto nacional. Assim fazendo o País poderá encontrar um equilíbrio entre estas ações, como indicado na figura 6 (B), de modo a promover o desenvolvimento sustentável tão desejado e que colocaria o Brasil em condições de competir, no cenário internacional, em condições de igualdade com os países desenvolvidos.
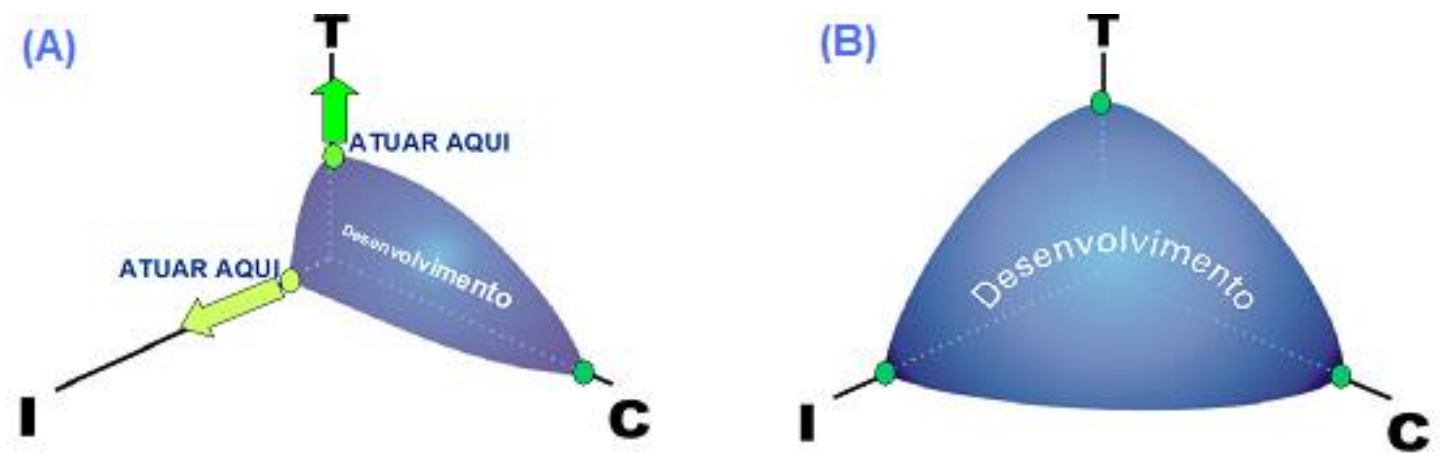

Figura 6 - Caracterização da CT\&I no Brasil: a) vigente b) desejada

Uma política de estado para enfrentar este desafio requer além do aumento dos investimentos em CT\&I e de um arcabouço legal apropriado, também e principalmente uma mudança de foco. Essa mudança de foco tem sido tentada no escopo dos Planos Governamentais para CT\&I como: o Plano de Ação da Ciência, Tecnologia e Inovação - PACTI e da Política de Desenvolvimento 
Produtivo - PDP e a Estratégia Nacional de CT\&I - ENCTI [7], isso para ficar em poucos exemplos. A ação indutora do poder público tem papel importante neste processo, não só no nível federal, mas também nos estados por meio das Fundações Estaduais de Amparo à Pesquisa. Ambos poderes, federal e estaduais, devem induzir e atuar como articuladores - via novos modelos de formação de pesquisadores - da aproximação das universidades e centros de pesquisa com o setor empresarial e as indústrias. No entanto estes planos acima mencionados têm falhado pela falta dos insumos básicos: recursos e arcabouço legal adequados.

A complexidade da ciência e a atual dimensão do Sistema Nacional de CT\&I requerem que sejam adotados esquemas flexíveis e robustos de financiamento à pesquisa, à semelhança do observado em outros países. O exemplo do Institutos Nacionais de CT\&I - INCTS indicava uma iniciativa importante na direção desejada. Os Institutos têm foco temático em uma área de conhecimento e objetivos como: impulsionar a pesquisa científica básica melhorando sua competitividade internacional, fortalecer a formação de recursos humanos na área e desenvolver pesquisa tecnológica de ponta associada à aplicações em estreita articulação com empresas inovadoras. No entanto a descontinuidade do programa - por falta de recursos - compromete as metas de uma politica mais perene e consistente para o País.

\section{INOVAÇÃO NAS EMPRESAS}

A tecnologia e a inovação se dão majoritariamente nas empresas - isso é o que tem ensinado os países desenvolvidos e os emergentes que vêm superando o Brasil com economias mais robustas. Portanto, outro desafio nacional é modernizar a indústria, motivá-la a fazer inovação, a desenvolver tecnologias próprias ao invés de comprar pacotes tecnológicos.

O elemento primordial de aceleração deste processo, praticado à exaustão nos países da Organização para a Cooperação e Desenvolvimento Econômico - OCDE, é a subvenção direta a empresas, especialmente às médias e pequenas que, sem esse incentivo, estão fadadas a desaparecer na feroz competição internacional. A subvenção econômica é definida como o investimento público de recursos, não reembolsáveis, em projetos específicos de inovação tecnológica das empresas. A subvenção é, portanto, o compartilhamento, dos custos e riscos da pesquisa e desenvolvimento, entre a empresa e o estado.

No século passado, existiu grande resistência de agentes públicos e da academia, principalmente no seio das universidades públicas, quanto a essa modalidade de investimento. Felizmente essa visão vem mudando na medida em que muitos doutores vão sendo formados e conseguem desenvolver pesquisas que resultam em produtos de interesse da sociedade, como medicamentos, softwares e eletrônicos, para ficar em poucos exemplos.

Produtos inovadores não serão produzidos (em larga escala) nas universidades e sim transferidos para empresas já existentes, ou que irão gerar novas empresas eles mesmos (start ups e spin offs). Empresas essas que precisam do incentivo à inovação tecnológica para se estabelecerem e começarem a gerar empregos, produzir renda e recolher impostos.

Exemplos já começam a ser frequentes no Brasil, de empreendimentos que, assim criados, recolhem hoje milhares de vezes mais reais em impostos anuais do que o investimento público que lhes deu a chance de se instalar. A tabela 2 demonstra que este tipo de empresa gera mais empregos, fatura mais e agrega maior valor aos seus produtos.

Outros indicadores relevantes também são apresentados na tabela 2 que demonstra que as empresas inovadoras pagam melhores salários, tem empregados de melhor escolaridade e que permanecem mais tempo no emprego. 
Tabela 2 - Desempenho de empresas que inovam frente às tradicionais (fonte ABDI)

\begin{tabular}{|c|c|c|c|}
\hline EMPRESAS & Emprego & $\begin{array}{l}\text { Faturamento } \\
(\mathrm{R} \$ 1.000)\end{array}$ & $\begin{array}{l}\text { Valor Adicionado } \\
\quad(\mathrm{R} \$ 1.000)\end{array}$ \\
\hline Inovam e diferenciam produto & 545,9 & 135,5 & 51,1 \\
\hline $\begin{array}{l}\text { Especializadas em produtos } \\
\text { padronizados }\end{array}$ & 158,1 & 25,7 & 10,6 \\
\hline Não diferenciam produto & 34,2 & 1,3 & 0,45 \\
\hline EMPRESAS & $\begin{array}{c}\text { Remuneração } \\
\text { R\$/mês }\end{array}$ & $\begin{array}{l}\text { Escolaridade } \\
\text { (anos) }\end{array}$ & $\begin{array}{c}\text { Tempo no Emprego } \\
\text { (meses) }\end{array}$ \\
\hline Inovam e diferenciam produto & 1.255 & 9,13 & 54,09 \\
\hline $\begin{array}{l}\text { Especializadas em produtos } \\
\text { padronizados }\end{array}$ & 749 & 7,64 & 43,90 \\
\hline Não diferenciam produto & 431 & 6,89 & 35,41 \\
\hline
\end{tabular}

É estratégico para o País, portanto, avançar nessas políticas e fazer a subvenção. Isso é necessário e urgente para levar o conhecimento científico produzido ao ponto em que venha aperfeiçoar a indústria, tanto na criação de novos produtos, quanto na melhoria da qualidade daqueles já existentes. Isso dará mais competitividade à indústria nacional, gerando mais trabalho, renda e impostos. Não fazê-lo significa ficar para trás na competição nacional e mundial.

Para buscar maior sucesso nessa política de CT\&I o País não pode prescindir da participação das agências de fomento em seus planejamentos e suas ações. As agências públicas estaduais FAPs já cumprem um papel essencial no processo, e podem cumpri-lo ainda com mais vigor dentro de uma política nacional consistente para o desenvolvimento científico e tecnológico. Um dos elementos importantes da participação das FAPs é a real possibilidade de aumento de recursos destinados à formação de pesquisadores. Levantamento recente do Conselho Nacional das Fundações Estaduais de Amparo à Pesquisa - CONFAP, indicou que nos últimos anos o orçamento efetivamente executado pelo conjunto dessas agências estaduais foi em torno de $\mathrm{R} \$ 2,6$ bilhões por ano. Este é um montante expressivo para que, somado aos investimentos federais e do setor empresarial, possa acelerar o desenvolvimento científico e tecnológico nacional assim como colocar a inovação nas empresas nacionais.

Outro aspecto relevante de contribuição das FAPs é sua capilaridade nacional. Com entidades estaduais de fomento à CT\&I em praticamente todos os estados da federação (exceção para Roraima) e com as dimensões continentais do Brasil, estas estruturas estaduais representam uma rede capaz de chegar ao País como um todo. Some-se ao aspecto anterior, o conhecimento que as FAPs têm de suas especificidades regionais e estaduais. Isso permite o uso mais adequado dos recursos federais em ações apropriadas para a realidade de cada estado.

\section{O CÓDIGO NACIONAL DE CT\&I}

Como já mencionado, o Governo Federal vem apresentando propostas para a área de CT\&I através do lançamento de documentos que mudam de nome a cada gestão. $\mathrm{O}$ mais recente, em discussão, e a ENCTI - Estratégia Nacional de Ciência, Tecnologia e Inovação. No entanto todos os planos nesta área, quaisquer que sejam, só têm sucesso caso dois insumos sejam garantidos: recursos robustos e perenes (já discutido) e arcabouço legal adequado.

Os diversos planos têm proposto incluir o tema da CT\&I como eixo estruturante do desenvolvimento do País apresentando diretrizes, definindo ações e estabelecendo os eixos de sustentação e as prioridades para o período de sua vigência. No entanto têm falhado no aporte dos investimentos, que deveriam ser da ordem de $2 \%$ do PIB anualmente, e da existência de um arcabouço legal adequado. 
É importante enfatizar que o arcabouço legal brasileiro tem sido, até aqui, um grande obstáculo para a execução das atividades de pesquisa e inovação. Um desestímulo para as indústrias. Mesmo que o recurso exista na medida necessária - o que não é o caso - a legislação vigente dificulta e, algumas vezes, impede a execução dos projetos. Proposta para solução desta questão surgiu em 2011, numa iniciativa do CONFAP e CONSECTI, em reunião conjunta em Belo Horizonte por ocasião do Jubileu de Prata da FAPEMIG e foi denominado Código Nacional de CT\&I. O documento produzido, por um grupo de procuradores, deu entrada na Câmara Federal, com a adesão de várias entidades, na forma do projeto de lei: PL 2177/2011.

Decorridos quase 5 anos de tramitação, dever-se-ia comemorar a sanção do Código (PLC 77/2015), ocorrida no dia 11 de janeiro de 2016, que se transformou na Lei 13.243/2016. Entretanto a Presidente da República optou por, ouvido os Ministérios do Planejamento e da Fazenda, vetar oito itens do texto encaminhado para sanção pelo Congresso Nacional. Vale destacar que - de forma excepcional na história do Congresso Nacional - o projeto foi aprovado por unanimidade tanto na Câmara como no Senado Federal. É importante enfatizar que as aprovações ocorreram após vários anos de discussões com efetiva participação da sociedade em diversas audiências públicas. Somese a isso o fato de que 20 entidades acadêmicas, de ciência, de tecnologia e empresariais enviaram um ofício à Presidente, solicitando a sanção sem vetos - o documento não foi considerado.

Tem sido dito a exaustão que o Brasil vai bem na ciência, já tendo alcançado a décima terceira posição mundial de produção científica indexada, mas vai mal na inovação onde amarga a sexagésima oitava posição. Isso significa que o País faz pesquisa de alto nível com qualidade internacional, mas não consegue transformar o conhecimento gerado em riqueza e desenvolvimento para a sociedade. O Código Nacional de CT\&I tem o objetivo de superar esses obstáculos incentivando a inovação. Porém os vetos, de natureza puramente burocrática, descaracterizam o texto original dificultando ou impedindo o alcance deste objetivo.

Dessa forma é necessário e urgente que a sociedade brasileira se articule com o Congresso Nacional visando a derrubada dos vetos que - se concretizada - vai garantir que o Código possa trazer as condições necessárias para, a médio e longo prazos, garantir a competividade dos produtos nacionais gerando riqueza e desenvolvimento sustentável para o País.

\section{CONCLUSÃO}

Para que o País possa - de fato - se tornar competitivo no cenário internacional e se colocar, de forma sustentável, como potência econômica, científica, tecnológica e social, este artigo construiu algumas recomendações enfatizadas a seguir.

Aumento dos investimentos direcionados em P\&D para 2\% do PIB, em 10 anos. O Brasil tem a oportunidade, nos próximos 10 anos, de consolidar-se no cenário mundial de CT\&I como um País de produção competitiva e portador de política arrojada. Para isso precisará garantir: a perenidade das Políticas de Estado; que as agências federais tenham seus orçamentos ampliados e que as FAPs em todos os estados tenham seus orçamentos cumpridos conforme estabelecido nas respectivas legislações.

Consolidação do arcabouço legal (Código Nacional de CT\&I - Lei 13.423/2016) e das práticas de controle para fins de compatibilização com as especificidades da pesquisa e da inovação. Diferentemente dos demais órgãos que integram a administração pública, as agências de fomento requerem, justamente pela especificidade de sua atividade fim, trato diferenciado. É necessário ocorrer uma ampla discussão nos Poderes Legislativo e Executivo com o objetivo de simplificar os procedimentos - regulamentação. Quanto à necessária fiscalização e controle externo exercidos pelos Órgãos de Controle, seja em âmbito federal ou estadual, entende-se que eles devam ser e adaptados à nova legislação. 
Aperfeiçoamento da interação entre o governo, as universidades e as empresas. A Lei 13.243/2016 estabelece medidas de incentivo à inovação e à pesquisa científica e tecnológica no ambiente empresarial, com vistas à capacitação e ao alcance da autonomia tecnológica e ao desenvolvimento industrial. As empresas precisam estar convencidas de que a inovação tecnológica em seus produtos e processos proporcionará maior competitividade e que a aliança com os órgãos governamentais de fomento à pesquisa e com a comunidade científica tem muito a colaborar com o sucesso dessa pretensão.

Ainda vale mencionar que os pesquisadores e cientistas que desempenham as atividades de pesquisa e pós-graduação, não podem ser incluídos na mesma categoria de um servidor público que presta serviços de natureza meramente administrativa, subsequentemente, suas atividades não podem circunscreverem-se tão somente ao exercício de atividades acadêmicas. O pesquisador pode e deve, além de promover a inovação, participar da inserção do resultado de sua pesquisa no mercado produtivo como reza o Código Nacional de CT\&I.

\section{REFERÊNCIAS BIBLIOGRÁFICAS}

1. White, M., Rivalidades Produtivas, ISBN 8501062006, Editora Record.

2. Revista Science, 3 December 2010 vol 330, issue 6009, p 1273-1440.

3. CAPES - http://geocapes.capes.gov.br/geocapes2/

4. Borges, M. N. e Vilela, E. F., Developing Strategies: Minas Gerais Science and Technology Parks. Artigo publicado nos anais do XXVII IASP World Conference on Science and Technology Parks, 2010. Daedok, Coreia do Sul.

5. iNOVA, Uma proposta de modernização da educação em engenharia no Brasil. Publicado pela Confederação Nacional da Indústria - CNI, 2006.

6. CNI, O Estado da Inovação no Brasil, disponível em: http://arquivos.portaldaindustria.com.br/app/conteudo_24/2014/08/21/506/AGENDA_MEI2015_WEB2 .pdf

7. MCTI - ENCTI, disponível em:

http://www.mcti.gov.br/documents/10179/35540/Estrat\%C3\%A9gia+Nacional+de+Ci\%C3\%AAncia\% 2C\%20Tecnologia+e+Inova\%C3\%A7\%C3\%A3o+\%28Encti\%29\%202016-2019+-

+documento+para+discuss\%C3\%A3o/5a4fe994-955e-4658-a53c-bc598af09f7e 